\title{
Probabilistic sensitivity analysis of two suspension bridges in Istanbul, Turkey to near- and far-fault ground motion
}

\author{
Ö. Çavdar \\ Gümüşhane University, Department of Civil Engineering, 29000, Gümüşhane, Turkey \\ Correspondence to: Ö. Çavdar (ozlem_cavdar@ hotmail.com)
}

Received: 1 October 2011 - Revised: 12 December 2011 - Accepted: 13 December 2011 - Published: 28 February 2012

\begin{abstract}
The aim of this paper is to compare the near-fault and far-fault ground motion effects on the probabilistic sensitivity dynamic responses of two suspension bridges in Istanbul. Two different types of suspension bridges are selected to investigate the near-fault (NF) and far-fault (FF) ground motion effects on the bridge sensitivity responses. NF and FF strong ground motion records, which have approximately identical peak ground accelerations, of the Kocaeli (1999) earthquake are selected for the analyses. Displacements and internal forces are determined using the probabilistic sensitivity method (PSM), which is one type of stochastic finite element method. The efficiency and accuracy of the proposed algorithm are validated by comparison with results of the Monte Carlo Simulation (MCS) method. The displacements and internal forces obtained from the analyses of suspension bridges subjected to each fault effect are compared with each other. It is clearly seen that there is more seismic demand on displacements and internal forces when suspension bridges are subjected to NF and FF ground motion.
\end{abstract}

\section{Introduction}

Bridges have contributed to the development of civilization for a long time. The suspension bridges, Fatih Sultan Mehmet and Bosporus Bridges, located on Bosporus straits in Istanbul, a mega city of significant seismic hazard in Turkey. Istanbul has a population of approximately 15 million people and is located astride the Bosporus River, which divides it into European and Asian side. Suspension types of bridges are becoming more and more popular in the construction of long span bridges due to their many advantages, i.e. light in weight, efficient in load resistance, and of smaller cross sections. Suspension bridges which consist of main girders, towers and hanger are complicated structures. The hangers are vertical and connect to the deck and cable with singly hinged bearing. There are several factors af- fecting the dynamic response of suspension bridges to earthquake ground motions (Adanur, 2003).

Near fault ground motions have been recorded in major earthquakes such as 1999 Taiwan Chi-Chi, 1989 Loma Prieta, 1994 US Northridge, 1995 Japan Hyogoken-Nanbu and 1999 Kocaeli earthquake in Turkey, and it is noticed that they have large velocity pulses. It produces high input energy on structures in the beginning of the earthquake. The ground motions with the velocity pulses recorded in the vicinity of an earthquake fault are quite different from the usual far-fault earthquake ground motions. Comparison of the near-fault strong ground motion velocities with far-fault strong ground motions is shown in Fig. 1. These pulses are strongly influenced by the orientation of the fault, the direction of slip on the fault and the location of the recording station relative to the fault, which is termed as "directivity effect" due to the propagation of the rupture toward the recording site (Agrawal and He, 2002; Somerville, 2003; Megawati et al., 2001; Wang et al., 2002). The velocity pulse duration in the near-fault ground motions is larger than $1.0 \mathrm{~s}$. In addition, the ratio of the peak ground velocity (PGV) to the peak ground acceleration (PGA) of the near-fault ground motions is larger than $0.1 \mathrm{~s}$. The ground motions having these characteristics expose the structure to high input energy in the beginning of the earthquake (Liao et al., 2004) and cause large structural responses. Therefore, structural response to nearfault ground motions has received much attention in recent years. So far, dynamic response analyses of some structures subjected to near-fault ground motions have been performed (Liao et al., 2004; Hall et al., 1995; Malhotra, 1999; Chopra and Chintanapakdee, 2001). In these studies, it is seen that long period structures such as frame buildings and bridges experience a higher dynamic response when they are subjected to near-fault ground motion.

The effects of NF and FF ground motion on many civil engineering structures such as buildings, tunnels, bridges, nuclear station, etc. have been investigated in many recent 


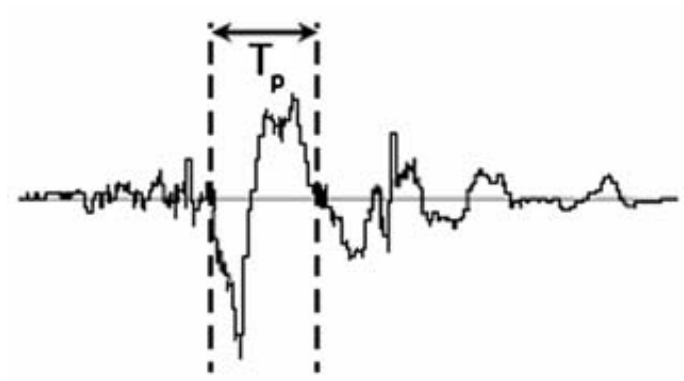

(a) Near Fault Strong Ground Motion

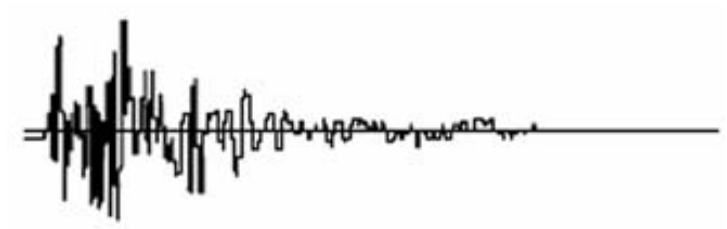

(b) Far Fault Strong Ground Motion

Fig. 1. The time-histories of two different strong ground motion velocities.

studies (Megawati et al., 2001; Liao et al., 2004; Chopra and Chintanapakdee, 2001; Bertero et al., 1978; Hall et al., 1995; Corigliano et al., 2006; Özturk, 2006; Dicleli and Buddaram, 2007; Liao et al., 2001; Bayraktar et al., 2008). Megawati et al. (2001) derived the ground motions at the piers from the vibration records of the towers to discuss the possibility of the rupture in the step-over by examining these ground motions. Liao et al. (2004) studied the dynamic behavior of a five-span concrete pier bridge subjected to both near-fault and far-field ground motions. Liao et al. (2001) investigated the dynamic response of seismic isolated continuous girder bridges subjected to either near-fault or far-field ground motions as compared to the non-isolated ones. It can be clearly seen from these studies that the importance of near-fault ground motion effect on the response of the structures has been highlighted. These studies were based on the assumption of complete determinacy of structural parameters. This is usually referred to as deterministic analysis. In reality, however, there are uncertainties in design variables. These uncertainties include geometric properties, material mechanical properties, load magnitude and distribution, etc. Therefore, deterministic analysis cannot provide complete information regarding dynamic responses of long-span bridges with cables. To identify changes in the material and geometrical properties of a bridge, probabilistic sensitivity method (PSM) is required. The probabilistic sensitivity method (PSM) for structures has been developed by several researchers (Kleiber and Hien, 1992; Hien and Kleiber, 1991; Çavdar et al., 2010; Juhn and Manolis, 1992; Melchers and Ahammed, 2004; Cheng and
Xiao, 2005; Liu et al., 1999). The concept of probabilistic sensitivity, aims to find the expectations and the sensitivity response for changes in the structural response due to structural parameter variations. The probabilistic sensitivity analysis of any structural system involves computation of the derivatives of the structural response quantities like displacements, strains, stresses, eigenvalues, eigenvectors etc. Very few researchers (Cheng and Xiao, 2005; Liu et al., 1999) have studied the random variable material and geometrical properties of long-span bridges having steel cables. Cheng and Xiao (2005) proposed a finite-element-based algorithm for the probabilistic free vibration and flutter analyses of suspension bridges. Liu et al. (1999) showed that large-flexible structures, such as suspension bridges, actually possess random material properties and that these random properties unavoidably affect the dynamic system parameters. However, there has been no sufficient research about the near-fault and far-fault ground motion effect on the stochastic sensitivity finite element analysis of complex suspension bridges.

The main objective of this paper is to compare the probabilistic sensitivity earthquake response of suspension bridges subjected to both near-fault and far-fault ground motion excitations. For this purpose, the detailed two-dimensional structural finite element models of Bosporus and Fatih Sultan Mehmet bridges were prepared and the probabilistic dynamics sensitivity was made. The Kocaeli earthquake records that displayed a ground motion with apparent velocity pulse are selected to represent the near-fault earthquake characteristics. For comparison, earthquake ground motions recorded at the same site from Kocaeli earthquake, the epicenter of which is far away from the site, are employed as the far-fault ground motions, to illustrate the difference between the NF and FF earthquake characteristics. Only the vertical component of the ground motions is used as input to determine the probabilistic dynamic behavior of the suspension bridges. During probabilistic dynamics sensitivity analysis, displacements and internal forces of the systems are obtained from PSM and MCS methods by using different uncertainties of material properties. Elastic modulus is chosen as the random variable material properties. The analysis results obtained from these two methods are compared with each other.

This work carries a great importance due to the fact that it includes the probabilistic dynamics sensitivity analysis of the Bosporus and Fatih Sultan Mehmet Bridges as well as earthquake performance under the action of the Kocaeli earthquake for both bridges in the same work.

\section{The Probabilistic Sensitivity Method (PSM)}

The concept of probabilistic sensitivity aims to find the expectations and sensitivity response for changes in the structural response due to structural parameter variations. Structural response sensitivity of multi-degrees-of-freedom dynamic systems is considered. Both the time interval and 


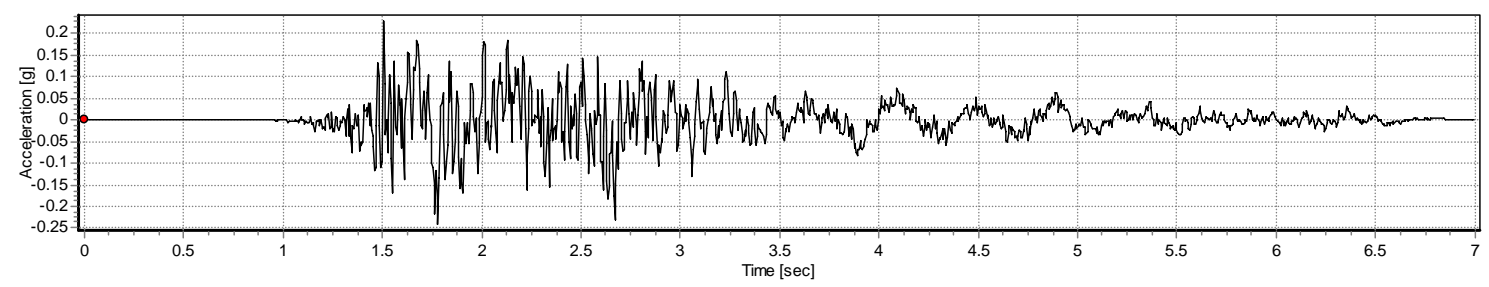

(a) The time-histories of ground motion acceleration

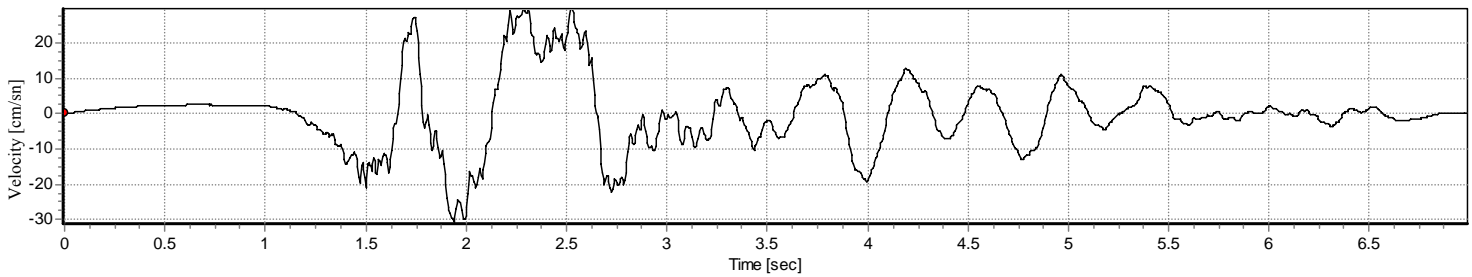

(b) The time-histories of ground motion velocity

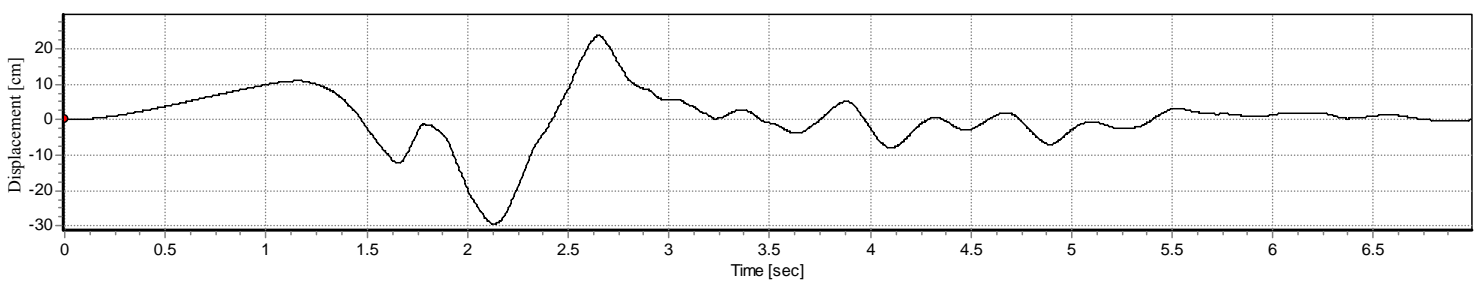

(c) The time-histories of ground motion displacement

Fig. 2. Acceleration (a) velocity (b) and displacement (c) time-histories for near-fault ground motion recorded at Yarimca in Kocaeli earthquake.

time instant response sensitivities are considered here in the context of probabilistic behavior. This paper deals with random displacement sensitivity when the structure involves the modulus of elasticity $(E)$ as a random parameter.

A deterministic equation of motion can be written as

$M_{\alpha \beta} \ddot{q}_{\beta}+C_{\alpha \beta} \dot{q}_{\beta}+K_{\alpha \beta} q_{\beta}=Q_{\alpha}$

where $K_{\alpha \beta}, M_{\alpha \beta}, C_{\alpha \beta}$ denote the stiffness matrix, mass matrix and damping matrix, $\ddot{q}_{\beta}, \dot{q}_{\beta}, q_{\beta}$ denote the acceleration, velocity, displacement, respectively. The probabilistic perturbation based approach consists usually of the up to the second order equations obtained starting from the deterministic ones.

The objective of the probabilistic sensitivity analysis is to determine changes in the structural response functional with variations in design parameters.

For a linear elastic system with $N$ degrees of freedom, consider the system response over the time interval $[0, \mathrm{~T}]$ described by the integral functional (Kleiber and Hien, 1992; Hien and Kleiber, 1991).

$\varphi\left(h^{d}, b_{p}\right)=\int_{0}^{\tau} \mathrm{G}\left[q_{\alpha}\left(h^{d}, b_{p} ; \tau\right), h^{d}\right] d_{\tau}$

$d=1,2, \ldots, D ; \rho=1,2 \ldots, N ; \alpha=1,2, \ldots, N$

where $G$ is a given function of its arguments, $h^{d}$ is a $D$ dimensional design variable vector, $b_{p}$ is an $\tilde{N}$-dimensional random variable vector and $q_{\alpha}$ is an $N$-dimensional vector of nodal displacement-type variables.

The nodal displacement-type variables $q_{\alpha}\left(h^{d}, b_{p} ; \tau\right)$ are implicit functions of the random and design variables and satisfy the spatially discredited equation of motion of the form:

Zeroth-order equation ( $€^{0}$ terms, one pair of systems of $N$ linear simultaneous ordinary differential equations for $q_{\beta}^{0}\left(h^{d}, b_{\rho}^{0} ; \tau\right)$ and $\lambda_{\alpha}^{0}\left(h^{d}, b_{\rho}^{0} ; \tau\right) \tau \epsilon[0, T]$, respectively).

$M_{\alpha \beta}^{0}\left(h^{d}, b_{\rho}^{0}\right) \ddot{q}_{\beta}^{0}\left(h^{d}, b_{\rho}^{0} ; \tau\right)+C_{\alpha \beta}^{0}\left(h^{d}, b_{\rho}^{0}\right) \dot{q}_{\beta}^{0}\left(h^{d}, b_{\rho}^{0} ; \tau\right)$

$+K_{\alpha \beta}^{0}\left(h^{d}, b_{\rho}^{0}\right) q_{\beta}^{0}\left(h^{d}, b_{\rho}^{0} ; \tau\right)=Q_{\alpha}^{0}\left(h^{d}, b_{\rho}^{0} ; \tau\right)$

together with the homogeneous initial conditions

$q_{\alpha}^{0}\left(h^{a}, b_{\rho} ; 0\right)=0 ; \dot{q}_{\alpha}^{0}\left(h^{a}, b_{\rho} ; 0\right)=0 ;$

$M_{\alpha \beta}^{0}\left(h^{d}, b_{\rho}^{0}\right) \ddot{\lambda}_{\beta}^{0}\left(h^{d}, b_{\rho}^{0} ; \tau\right)-C_{\alpha \beta}^{0}\left(h^{d}, b_{\rho}^{0}\right) \dot{\lambda}_{\beta}^{0}\left(h^{d}, b_{\rho}^{0} ; \tau\right)$

$+K_{\alpha \beta}^{0}\left(h^{d}, b_{\rho}^{0}\right) \lambda_{\beta}^{0}\left(h^{d}, b_{\rho}^{0} ; \tau\right)=G_{\alpha}^{0}\left(h^{d}, b_{\rho}^{0} ; \tau\right)$

$\lambda_{\alpha}^{0}\left(h^{d}, b_{\rho} ; T\right)=0 ; \quad \dot{\lambda}_{\alpha}^{0}\left(h^{d}, b_{\rho} ; T\right)=0$

First-order equations, $\left(€^{1}\right.$ terms, $\tilde{N}$-pairs systems of $N$ linear simultaneous ordinary differential equations for $q_{\alpha}^{, \rho}\left(h^{d}, b_{\rho} ; \tau\right) ; \lambda_{\alpha}^{\rho}\left(h^{d}, b_{\rho}^{0}, \tau\right), \tau \epsilon[0, T]$, respectively. $)$

$M_{\alpha \beta}^{0}\left(h^{d}, b_{\rho}^{0}\right) \ddot{q}_{\beta}^{, \rho}\left(h^{d}, b_{\rho}^{0} ; \tau\right)+C_{\alpha \beta}^{0}\left(h^{d}, b_{\rho}^{0}\right) \dot{q}_{\beta}^{, \rho}\left(h^{d}, b_{\rho}^{0} ; \tau\right)$ 


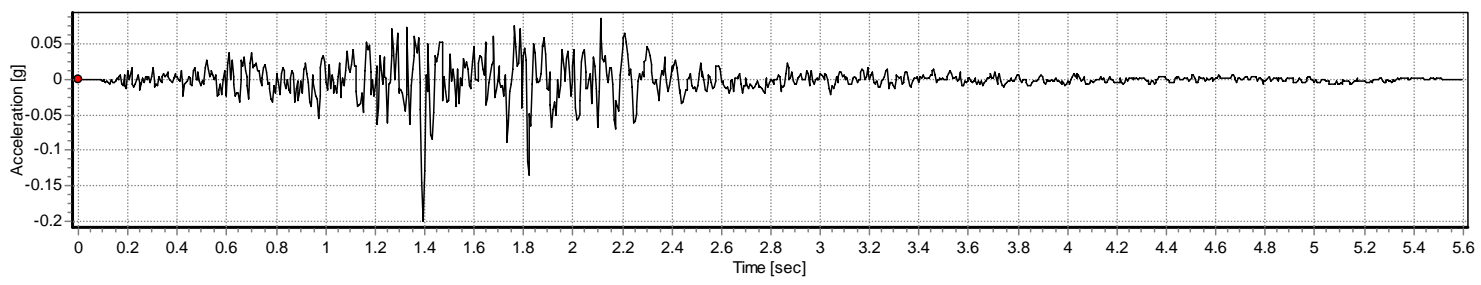

(a) The time-histories of ground motion acceleration

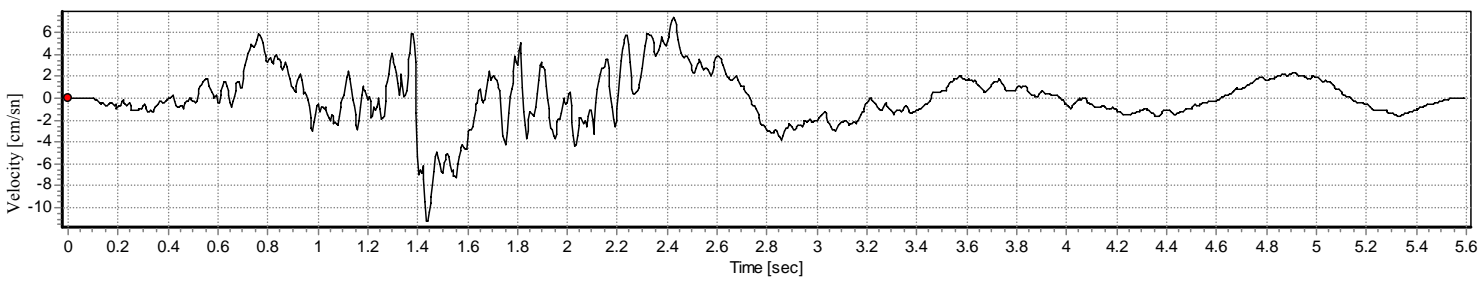

(b) The time-histories of ground motion velocity

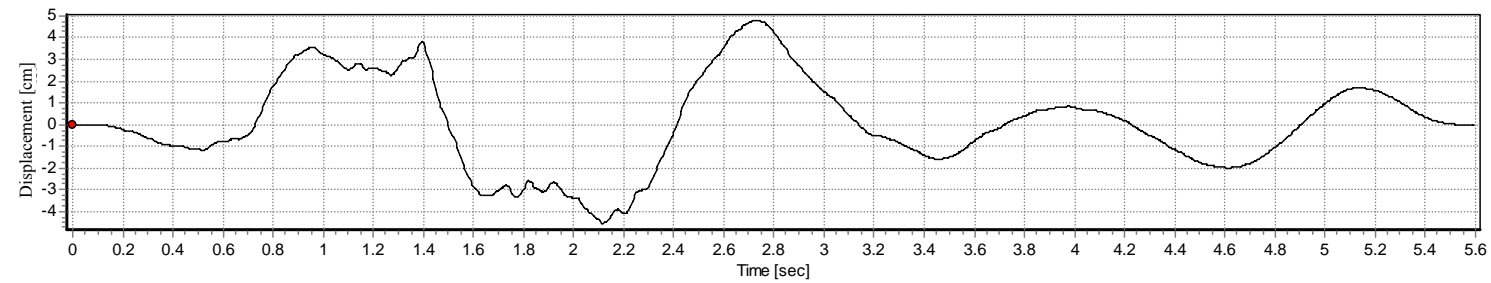

(c) The time-histories of ground motion displacement

Fig. 3. Acceleration (a) velocity (b) and displacement (c) time-histories for far-fault ground motion recorded at Gebze in Kocaeli earthquake.

$+K_{\alpha \beta}^{0}\left(h^{d}, b_{\rho}^{0}\right) q_{\beta}^{, \rho}\left(h^{d}, b_{\rho}^{0} ; \tau\right)=Q_{\alpha}^{\rho}\left(h^{d}, b_{\rho}^{0} ; \tau\right)$

$q_{\alpha}^{, \rho}\left(h^{d}, b_{\rho}^{0} ; \tau\right)=0 ; \dot{q}_{\alpha}^{, \rho}\left(h^{d}, b_{\rho} ; 0\right)=0$

$M_{\alpha \beta}^{0}\left(h^{d}, b_{\rho}^{0}\right) \ddot{\lambda}_{\beta}^{, \rho}\left(h^{d}, b_{\rho}^{0} ; \tau\right)-C_{\alpha \beta}^{0}\left(h^{d}, b_{\rho}^{0}\right) \dot{\lambda}_{\beta}^{, \rho}\left(h^{d}, b_{\rho}^{0} ; \tau\right)$

$+K_{\alpha \beta}^{0}\left(h^{d}, b_{\rho}^{0}\right) \lambda_{\beta}^{, \rho}\left(h^{d}, b_{\rho}^{0} ; \tau\right)=G_{\alpha}^{\rho}\left(h^{d}, b_{\rho}^{0} ; \tau\right)$

$\lambda_{\alpha}^{, \rho}\left(h^{d}, b_{\rho} ; T\right)=0 ; \quad \dot{\lambda}_{\alpha}^{, \rho}\left(h^{d}, b_{\rho} ; T\right)=0, \quad \rho=1,2 \ldots, \tilde{N}$

Second-order ( $€^{2}$ terms, one pair of systems of $N$ linear simultaneous ordinary differential equations for; $q_{\alpha}^{(2)}\left(h^{d}, b_{\rho}^{0} ; \tau\right) \operatorname{and} \lambda_{\alpha}^{(2)}\left(h^{d}, b_{\rho}^{0} ; \tau\right), \tau \varepsilon[0, T]$, respectively. $)$

$M_{\alpha \beta}^{0}\left(h^{d}, b_{\rho}^{0}\right) \ddot{q}_{\beta}^{(2)}\left(h^{d}, b_{\rho}^{0} ; \tau\right)+C_{\alpha \beta}^{0}\left(h^{d}, b_{\rho}^{0}\right) \dot{q}_{\beta}^{(2)}\left(h^{d}, b_{\rho}^{0} ; \tau\right)+$

$K_{\alpha \beta}^{0}\left(h^{d}, b_{\rho}^{0}\right) q_{\beta}^{(2)}\left(h^{d}, b_{\rho}^{0} ; \tau\right)=Q_{\alpha}^{(2)}\left(h^{d}, b_{\rho}^{0} ; \tau\right)$

$q_{\alpha}^{(2)}\left(h^{d}, b_{\rho} ; 0\right)=0 ; \dot{q}_{\alpha}^{(2)}\left(h^{d}, b_{\rho} ; 0=0\right)$

$M_{\alpha \beta}^{0}\left(h^{d}, b_{\rho}^{0}\right) \ddot{\lambda}_{\beta}^{(2)}\left(h^{d}, b_{\rho}^{0} ; \tau\right)-C_{\alpha \beta}^{0}\left(h^{d}, b_{\rho}^{0}\right) \dot{\lambda}_{\beta}^{(2)}\left(h^{d}, b_{\rho}^{0} ; \tau\right)$

$+K_{\alpha \beta}^{0}\left(h^{d}, b_{\rho}^{0}\right) \lambda_{\beta}^{(2)}\left(h^{d}, b_{\rho}^{0} ; \tau\right)=G_{\alpha}^{(2)}\left(h^{d}, b_{\rho}^{0} ; \tau\right)$

$\lambda_{\alpha}^{(2)}\left(h^{d}, b_{\rho} ; T\right)=0 ; \dot{\lambda}_{\alpha}^{(2}\left(h^{d}, b_{\rho} ; T\right)=0$
In Eqs. (3)-(5) the indices run over the following sequence:

$q_{\alpha}^{(2)}\left(h^{d}, b_{\rho}^{0}, \tau\right)=q_{\alpha}^{\rho \sigma}\left(h^{d}, b_{\rho}^{0} ; \tau\right) S_{b}^{\rho \sigma}$

$\lambda_{\alpha}^{(2)}\left(h^{d}, b_{\rho}^{0} ; \tau\right)=\lambda_{\alpha}^{, \rho \sigma}\left(h^{d}, b_{\rho}^{0} ; \tau\right) S_{b}^{\rho \sigma} \quad \rho, \sigma=1,2, \ldots, \tilde{N}$.

In Eqs. (4)-(5) the first and second order primary and adjoint generalized load vectors are denoted by:

$Q_{\alpha}^{\rho}\left(h^{d}, b_{\ell}^{0} ; \tau\right)=Q_{\alpha}^{, \rho}\left(h^{d}, b_{\ell}^{0} ; \tau\right)-$

$\left[\begin{array}{l}M_{\alpha \beta}^{, \rho}\left(h^{d}, b_{\ell}^{0}\right) \ddot{q}_{\beta}^{0}\left(h^{d}, b_{\ell}^{0} ; \tau\right) \\ +C_{\alpha \beta}^{, \rho}\left(h^{d}, b_{\ell}^{0}\right) \dot{q}_{\beta}^{0}\left(h^{d}, b_{\ell}^{0} ; \tau\right)+K_{\alpha \beta}^{, \rho}\left(h^{d}, b_{\ell}^{0}\right) q_{\beta}^{0}\left(h^{d}, b_{\ell}^{0}, \tau\right)\end{array}\right]$ (7)

$G_{\alpha}^{\rho}\left(h^{d}, b_{\ell}^{0} ; \tau\right)=G_{\alpha}^{, \rho}\left(h^{d}, b_{\ell}^{0} ; \tau\right)$

$-\left[\begin{array}{l}M_{\alpha \beta}^{, \rho}\left(h^{d}, b_{\ell}^{0}\right) \ddot{\lambda}_{\beta}^{0}\left(h^{d}, b_{\ell}^{0} ; \tau\right) \\ +C_{\alpha \beta}^{, \rho}\left(h^{d}, b_{\ell}^{0}\right) \dot{\lambda}_{\beta}^{0}\left(h^{d}, b_{\ell}^{0} ; \tau\right)+K_{\alpha \beta}^{, \rho}\left(h^{d}, b_{\ell}^{0}\right) \lambda_{\beta}^{0}\left(h^{d}, b_{\ell}^{0}, \tau\right)\end{array}\right]$

$Q_{\alpha}^{(2)}\left(h^{d}, b_{\ell}^{0} ; \tau\right)$

$=\left\{\begin{array}{l}Q_{\alpha}^{, \rho \sigma}\left(h^{d}, b_{\ell}^{0} ; \tau\right)-2\left[\begin{array}{l}M_{\alpha \beta}^{\rho}\left(h^{d}, b_{\ell}^{0}\right) \ddot{q}_{\beta}^{, \sigma}\left(h^{d}, b_{\ell}^{0} ; \tau\right) \\ +C_{\alpha \beta}^{\rho}\left(h^{d}, b_{\ell}^{0}\right) \dot{q}_{\beta}^{\sigma}\left(h^{d}, b_{\ell}^{0} ; \tau\right)+K_{\alpha \beta}^{, \rho}\left(h^{d}, b_{\ell}^{0}\right) q_{\beta}^{, \sigma}\left(h^{d}, b_{\ell}^{0} ; \tau\right)\end{array}\right] \\ -\left[\begin{array}{l}M_{\alpha \beta}^{\rho \sigma}\left(h^{d}, b_{\ell}^{0}\right) \ddot{q}_{\beta}^{0}\left(h^{d}, b_{\ell}^{0} ; \tau\right)+C_{\alpha \beta}^{\rho \sigma \sigma}\left(h^{d}, b_{\ell}^{0}\right) \dot{q}_{\beta}^{0}\left(h^{d}, b_{\ell}^{0} ; \tau\right) \\ +K_{\alpha \beta}^{, \rho \sigma}\left(h^{d}, b_{\ell}^{0}\right) q_{\beta}^{0}\left(h^{d}, b_{\ell}^{0} ; \tau\right)\end{array}\right]\end{array}\right\} S_{b}^{\rho \sigma}$

$G_{\alpha}^{(2)}\left(h^{d}, b_{\ell}^{0} ; \tau\right)$ 


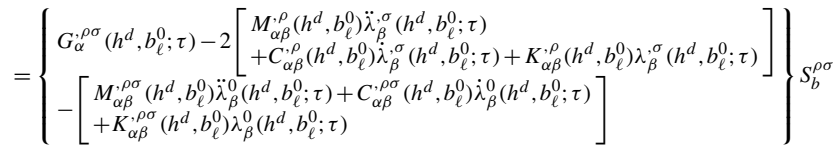

where $\tau$ is forward time variable, $\tilde{N}$ is the number of nodal random variables. $M_{\alpha \beta}^{0}, C_{\alpha \beta}^{0}$ and $K_{\alpha \beta}^{0}$ are system mass matrix, damping matrix and system stiffness matrix, respectively. $Q_{\alpha}^{0}, q_{\beta}^{0}$ and $N$ are load vector, displacement of the nodal random variable and the number of degrees of freedom in the system, respectively. $S_{b}^{\rho \sigma}$ is covariance matrix of nodal random variables. (. $)^{0}$ is zeroth-order quantities, taken at means of random variables, (.) ${ }^{, \rho}$ is first partial derivatives with respect to nodal random variables, and (.),$\rho \sigma$ is second partial derivatives with respect to nodal random variables.

The Monte Carlo Simulation generates a set of random values of $X$ according to its probability distribution function. The set can be written as $X=\left\{x_{1}, x_{2}, \ldots, x_{N}\right\}$, where $N$ is the number of simulation. For each values of $X$, the stiffness and mass matrices are computed. At the end of $\mathrm{N}$ simulations, we have a random set of displacement and stress values $\left\{\left\{q_{\beta}\right\}_{1},\left\{q_{\beta}\right\}_{2},\left\{q_{\beta}\right\}_{3}, \ldots,\left\{q_{\beta}\right\}_{N}\right\},\left\{\{\sigma\}_{1},\{\sigma\}_{2},\{\sigma\}_{3}, \ldots,\{\sigma\}_{N}\right\}$ for $X^{i}$. From this finite set of solutions, the expected values of displacement and stress are computed using the following formulas:

$\mu_{\left\{q_{\beta}\right\}}=\frac{1}{N} \sum_{i=1}^{N}\left\{q_{\beta}\right\}_{i}$

$\mu_{\{\sigma\}}=\frac{1}{N} \sum_{i=1}^{N}\{\sigma\}_{i}$

A direct Monte Carlo simulation (MCS) is also performed for comparison of results. The MCS method is a quite versatile mathematical tool capable of handling situations where all other methods fail to succeed; in structural dynamics, it has attracted intense attention only recently, following the widespread availability of inexpensive computational systems (Shinozuka, 1972). A sample global stiffness matrix is formed on the basis of probabilistic fields generated by means of the covariance matrix decomposition algorithm. The response sensitivity of the structure is determined by relying on the standard deterministic sensitivity analysis. This procedure is repeated several times to procedure an ensemble of the structural response sensitivity. In MCS, the random stiffness matrix needs to be inverted for each simulated structure, consuming an enormous amount of CPU time.

\section{Earthquake records selected for near-fault (NF) and far-fault (FF) ground motions}

In this study, the Kocaeli earthquake, 17 August 1999, has been used as the ground motion. The earthquake magnitude 7.4 occurred at Marmara Region in 1999, causing major human, social and economic losses in Turkey. The record at the
Yarimca station (Fig. 2) of the Kocaeli earthquake is selected to represent the characteristics of near-fault ground motion. The record at the Gebze station (Fig. 3) for the same earthquake is employed to represent the characteristics of far-fault ground motion. The properties of these records (Peer, 2011) are summarized in Table 1.

As shown in Figs. 2-3, the velocity pulse of the NF ground motion is found to be significant as compared to the far-fault ground motion. The NF ground motion possesses significantly long period velocity pulse. This long period response of the NF ground motion is more excessive than the one of the FF ground motion. Some important parameters, such as the ratio of PGV to PGA, normalized spectral velocity and the energy of the ground motion, are evaluated in the present study in order to discuss the feature of bridges sensitivity to NF and FF ground motions, where the normalized spectral velocity means the response spectral velocity obtained by scaling the PGA of the input ground motion to $0.242 \mathrm{~g}$. The peak ground acceleration of FF records is scaled up to $0.242 \mathrm{~g}$ in the analyses. This analysis is helpful for the engineering design of seismic suspension bridges. Figure 4 presents acceleration time-histories for scaled FF ground motions.

In order to investigate the near- and far-fault effects on the probabilistic response of suspension bridges, the earthquake analyses of the bridges are performed. The Kocaeli (1999) earthquake was recorded with the magnitude of 7.4 and this magnitude is the same for both records considered in this study. The distance of the recording site from the source is ranged from 2.6 to $17 \mathrm{~km}$. A scatter plot of the magnitudedistance pair for the records of strong ground motions is shown in Fig. 5. The record characterizing near-fault ground motion is obtained from the distance less than $10 \mathrm{~km}$ to epicenter and the other record characterizing far-fault ground motion is obtained from the distance more than $10 \mathrm{~km}$ to epicenter.

\section{Numerical examples}

The main objective of this work is to compare NF and FF strong ground motion effects on the earthquake probabilistic sensitivity response of suspension bridges. This is achieved by performing two methodologies, perturbation techniques associated with the PSM and MCS methods, offering practicing engineers an overview of the techniques typically employed in the analysis of the uncertain parameters of a structural system. For this purpose, two finite element models belong to Bosporus and Fatih Sultan Mehmet Bridges are used in the numerical analyses. The probabilistic sensivity method (PSM) is used to investigate the probabilistic dynamic response of the bridges, and to compare the NF and FF obtained from methods mentioned above by using different uncertainties of material characteristic (elastic modulus) and compare them with each other. 
Table 1. Properties of selected near-fault ground motion record (the component YPT-UP) and far-fault ground motion record (the component GBZ-UP) in Kocaeli Earthquake $(M=7.4), 17$ August 1999.

\begin{tabular}{llllllll}
\hline Ground motion & Component & Station & $\begin{array}{l}\text { Distance } \\
\text { to fault }(\mathrm{km})\end{array}$ & $\begin{array}{l}\text { PGA } \\
(\mathrm{g})\end{array}$ & $\begin{array}{l}\text { PGV } \\
(\mathrm{cm} / \mathrm{sn})\end{array}$ & $\begin{array}{l}\text { PGD } \\
(\mathrm{cm})\end{array}$ & $\begin{array}{l}\text { PGV/PGA } \\
(\mathrm{s})\end{array}$ \\
\hline $\begin{array}{l}\text { Near-Fault } \\
\text { Far-fault }\end{array}$ & YPT-UP & Yarimca & 2.6 & 0.242 & 30.8 & 29.55 & 0.129 \\
\hline
\end{tabular}

Table 2. Structural material and sectional properties of Bosporus Suspension Bridge (Adanur, 2003).

\begin{tabular}{llllll}
\hline Members & $\begin{array}{l}\text { Elastic modulus } \\
\left(\mathrm{kN} \mathrm{m}^{-2}\right)\end{array}$ & $\begin{array}{l}\text { Cables sectional } \\
\operatorname{area}\left(\mathrm{m}^{2}\right)\end{array}$ & $\begin{array}{l}\text { Moments of } \\
\text { inertia }\left(\mathrm{m}^{4}\right)\end{array}$ & $\begin{array}{l}\text { Poisson's } \\
\text { ratio }\end{array}$ & $\begin{array}{l}\text { Mass Density } \\
\left(\text { ton m }^{-3}\right)\end{array}$ \\
\hline Deck & $2.05 \times 10^{8}$ & 0.861 & 1.238 & 0.3 & 14.97 \\
Hanger & $1.62 \times 10^{8}$ & 0.0021 & $3.068 \times 10^{-7}$ & 0.3 & 8.004 \\
Main cable & $1.93 \times 10^{8}$ & 0.205 & $3.344 \times 10^{-3}$ & 0.3 & 8.629 \\
Backstay cable & $1.93 \times 10^{8}$ & 0.219 & $3.817 \times 10^{-3}$ & 0.3 & 8.334 \\
Tower & $2.05 \times 10^{8}$ & 0.68 & 4.9 & 0.3 & 7.85 \\
\hline
\end{tabular}

\subsection{Probabilistic sensitivity earthquake response of Bosporus Suspension Bridge}

The Bosporus Suspension Bridge, commissioned in 1973, joins the European and Asian Continents through Ortakoy and Beylerbeyi districts of Istanbul. It is a gravity-anchored suspension bridge with steel pylons and inclined hangers. The bridge has a main span of $1074 \mathrm{~m}$ (World rank 12th) and two side spans of $231 \mathrm{~m}$ and $255 \mathrm{~m}$ on the European and the Asian sides, respectively. The bridge has slender steel towers $165 \mathrm{~m}$ high, with a steel box-deck and inclined hangers. The horizontal distance between the cables is $28 \mathrm{~m}$ and the roadway is $21 \mathrm{~m}$ wide, accommodating three lanes each way. The roadway at the mid-span of the bridge is approximately $64 \mathrm{~m}$ a.s.l. The side span decks are not connected to the cable and the decks rest on piers taken to foundation level. The cost of the bridge amounted to USD 200 million (Adanur, 2003). General arrangement of the Bosporus Suspension Bridge is shown in Fig. 6. In addition, material and sectional properties such as main cable, back stay cable, hangers, deck, etc. of the Bosporus Suspension Bridge are shown in Table 2.

To investigate the probabilistic response of the Bosporus Suspension Bridge under to NF and FF ground motions, a two-dimensional mathematical model is used for calculations. Dumanoglu and Severn (1990) verified that 2-D analysis provides natural frequencies and mode shapes which are in close agreement with those obtained by 3-D analysis in the vertical direction for suspension bridges. The finite element model of Bosporus Suspension Bridge is shown in Fig. 7. As the deck, towers and cables are represented by beam elements, the hangers are represented by truss elements in the model. Because the side span decks are not connected to the cable, they are not considered in the finite element model. The finite element model of the Bosporus Suspension Bridge with inclined hangers has 161 nodal points, 159 beam elements and 118 truss elements and the model is represented by 469 degrees of freedom. This model has three degrees of freedom at each nodal point, namely, two translational degrees of freedom in vertical and longitudinal axes and one rotational degree of freedom in lateral axis.

The Bosporus suspension bridge is modeled by 277 probabilistic finite elements of different length. Elastic module from material properties is chosen as the random variable for the suspension bridge. The other variables are considered as deterministic. This random variable is assumed to follow a normal distribution with the coefficient of variation 0.10 . The respective expectation and correlation function and coefficient of variation for the elastic modulus $E_{\rho}$ are assumed as follows (Kleiber and Hien, 1992):

$$
\begin{aligned}
& E\left[E_{\rho}\right]=2.1 \times 10^{8} \quad \lambda=10 \\
& \mu\left(E_{\rho}, E_{\sigma}\right)=\exp \left(-\frac{\left|x_{\rho}-x_{\sigma}\right|}{\lambda l}\right) \quad \rho, \sigma=1,2, \ldots, 277
\end{aligned}
$$

$\alpha=0.10$

where $x_{\rho}, l$ and $\lambda$ are ordinates of the element midpoints (n random variable, $\rho, \sigma=1,2, \ldots, n$ ), structural member length and decay factor, respectively. The Bosporus suspension bridge is modeled by 277 probabilistic finite elements with different lengths. The MCS method is simulated for 10000 simulations. 


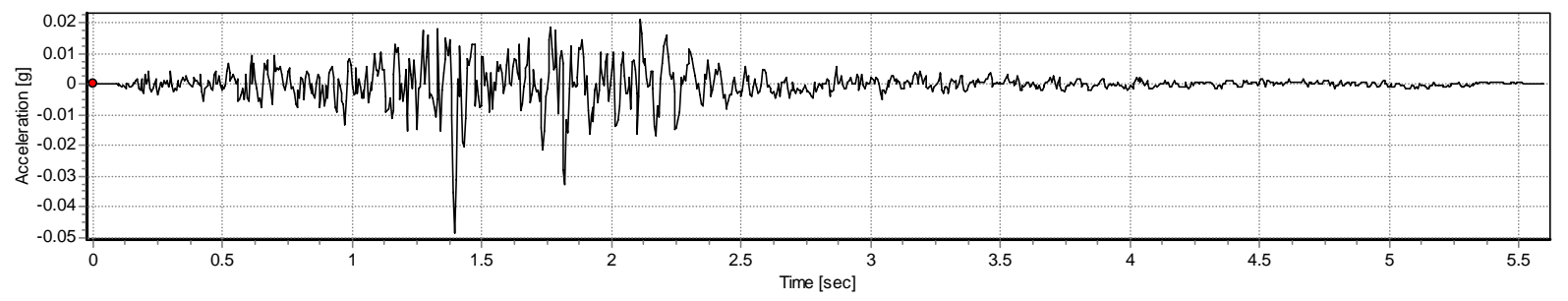

Fig. 4. Acceleration time-histories for scaled far-fault ground motion.

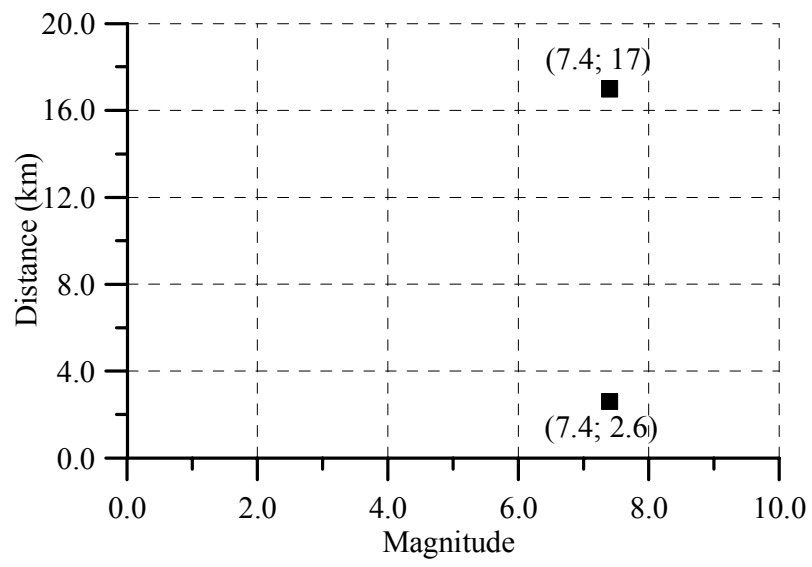

Fig. 5. Magnitude-distance distribution.

With the 2-D time-instant sensitivity response of the structural system of Fig. 7, the structural response functional is defined as

$\varphi(\tau)=\frac{\left[q_{\beta}(\tau)\right]^{2}}{\left(q_{\beta}^{(A)}\right)^{2}-1 \leq 0}$

where $q_{\beta}(\tau)$ is vertical displacement at the apex $\mathrm{A}$ and $q_{\beta}^{(A)}$ is an admissible displacement value. The elastic module is assumed to be random design variables.

Probabilistic dynamics sensitivity analyses response of multi-degrees-of-freedom suspension bridges is considered for NF and FF ground motion in this paper. The maximum displacements and internal forces of the suspension bridges are calculated according to Probabilistic Sensitivity Method (PSM) for NF and FF ground motions. The efficiency and accuracy of the proposed algorithm are validated by comparison with results of the Monte Carlo Simulation (MCS) method.

In the first part of this study, Bosporus Bridge probabilistic sensitivity responses with respect to random elastic modulus according to PSM and MCS methods are determined and compared with each other. The absolute maximum vertical displacement responses of the bridge deck and horizontal displacements along the Bosporus European tower obtained from PSM and MCS methods for NF and FF ground motion are presented in Fig. 8. Two analyses give very close results each other at the $1 / 3$ length distance from end of deck and at the top point of tower where maximum displacements occurred. The maximum displacements for the record YPT-UP and GBZ-UP of the Kocaeli earthquake occur as $66.80 \mathrm{~cm}$ and $12.29 \mathrm{~cm}$, respectively. The maximum horizontal displacements at tower for the record FF and NF occur as $5.21 \mathrm{~cm}$ and $1.04 \mathrm{~cm}$, respectively.

It is shown from Fig. 8 that the sensitivity displacement values for NF ground motion are greater than those for FF ground motion, although the peak ground acceleration of NF and FF records is the same. This situation is valid for both PSM and MCS response. The average absolute differences between NF and FF ground motions for vertical displacement values are about $84 \%$ for PSM.

Comparing PSM and MCS methods gives closer results to each other. The average absolute differences between these two methods for vertical displacement values are about $2.65 \%$ and $1.30 \%$, for NF and FF ground motions, respectively.

The maximum axial forces, shear forces and bending moments at the deck of the Bosporus Bridge obtained from probabilistic dynamics sensitivity analysis subjected to both NF and FF ground motion are presented Fig. 9. It is seen that maximum sensitivity internal forces are revealed by the NF and FF ground motions, and their values are higher for middle of deck measurements. Overall, maximum internal forces are higher for near-fault ground motion than far-fault. It is seen from Fig. 8 that values acquired from MCS and PSM methods are close to each other. As shown in Fig. 9, the minimum differences between the axial forces, shear forces and bending moments of these two methods are $0.06 \%, 0.09 \%$ and $0.18 \%$, respectively. Average differences for these internal forces are about $1.70 \%, 2.50 \%$ and $3.19 \%$, respectively.

\subsection{Probabilistic sensitivity earthquake response of Fatih Sultan Mehmet Suspension Bridge}

The Fatih Sultan Mehmet (Second Bosporus) Suspension Bridge, one of the world's longest modern type suspension bridges, is chosen as the second example to demonstrate the probabilistic response variation subject to both NF and FF ground motion. The bridge connecting the Europe and Asia 


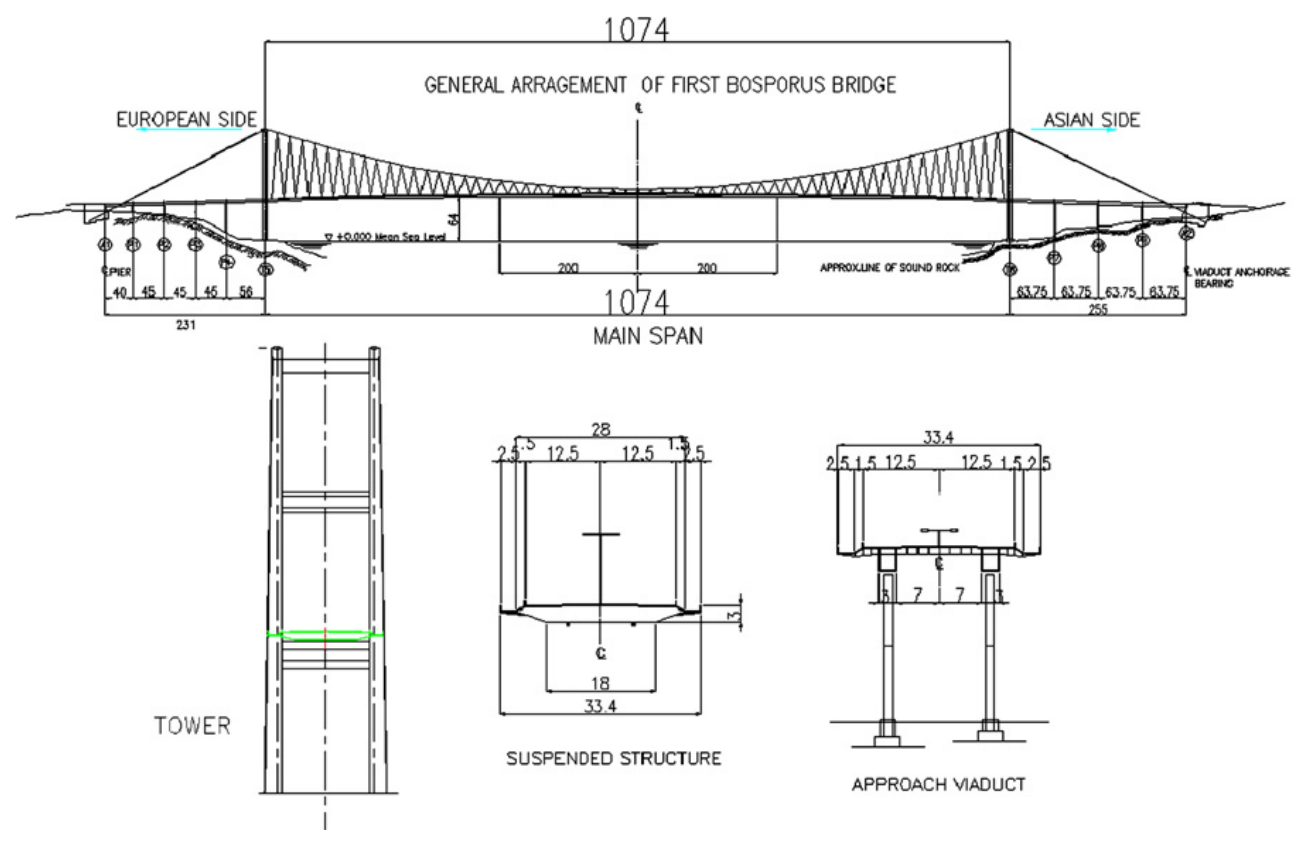

Fig. 6. General Arrangement of Bosporus Suspension Bridge.

Table 3. Structural material and sectional properties of Fatih Sultan Mehmet Suspension Bridge (Apayd $\iota n, 2002)$.

\begin{tabular}{llllll}
\hline Members & $\begin{array}{l}\text { Elastic modulus } \\
\left(\mathrm{kN} \mathrm{m}^{-2}\right)\end{array}$ & $\begin{array}{l}\text { Cables sectional } \\
\text { area }\left(\mathrm{m}^{2}\right)\end{array}$ & $\begin{array}{l}\text { Moments of } \\
\text { inertia }\left(\mathrm{m}^{4}\right)\end{array}$ & $\begin{array}{l}\text { Poisson's } \\
\text { ratio }\end{array}$ & $\begin{array}{l}\text { Mass Density } \\
\left(\text { ton } \mathrm{m}^{-3}\right)\end{array}$ \\
\hline Deck & $2.05 \times 10^{8}$ & 1.26 & 1.73 & 0.3 & 12.40 \\
Hanger & $1.93 \times 10^{8}$ & 0.0045 & - & 0.3 & 8.82 \\
Main cable & $1.93 \times 10^{8}$ & 0.367 & 0.0107 & 0.3 & 8.30 \\
Backstay cable & $1.93 \times 10^{8}$ & 0.392 & 0.0122 & 0.3 & 8.08 \\
Tower & $2.05 \times 10^{8}$ & $1.49-1.19$ & 6.41 & 0.3 & 7.85 \\
\hline
\end{tabular}

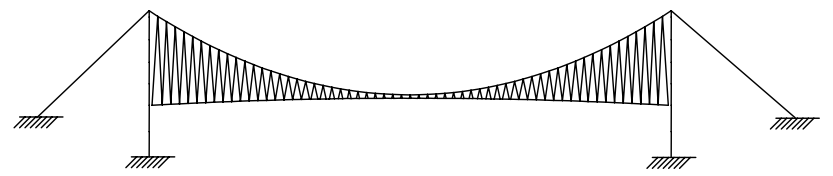

Fig. 7. Two-dimensional finite element model of Bosporus Suspension Bridge.

Continents in Istanbul, Turkey, has a box girder deck $39.4 \mathrm{~m}$ wide overall and $1090 \mathrm{~m}$ long. There are no side spans and the steel towers rise $110 \mathrm{~m}$ above ground level. The hangers are vertical and connect to the deck and cable with singly hinged bearing. The horizontal distance between the cables is $33.8 \mathrm{~m}$ and the roadway is $28 \mathrm{~m}$ wide, accommodating two four-lane highways. The roadway at the mid-span of the bridge is approximately $64 \mathrm{~m}$ above the sea level. General arrangement of the bridge is shown in Fig. 10. Also, cross- sectional properties of the elements of the bridge are presented in Table 3.

To analyze probabilistic dynamics sensitivity of the bridge model, a 2-D mathematical model is considered (Fig. 11). The fact that this 2-D model has relatively small number of degrees of freedom makes it more attractive by saving on computer time. Obviously, if actual design values for the responses are desired, a 3-D model should be taken into account. Although the 2-D bridge model includes some simplifications, it has been widely used in the literature and has been shown to capture the static and dynamic behavior of a 3-D model. Dumanoglu and Severn (1990) verified that 2-D analysis provides natural frequencies and mode shapes which are in close agreement with those obtained by 3-D analysis in the vertical direction for suspension bridges. Therefore, it is believed that the results based on the two-dimensional analyses are representative of the actual 3-D long-span bridge structures. 


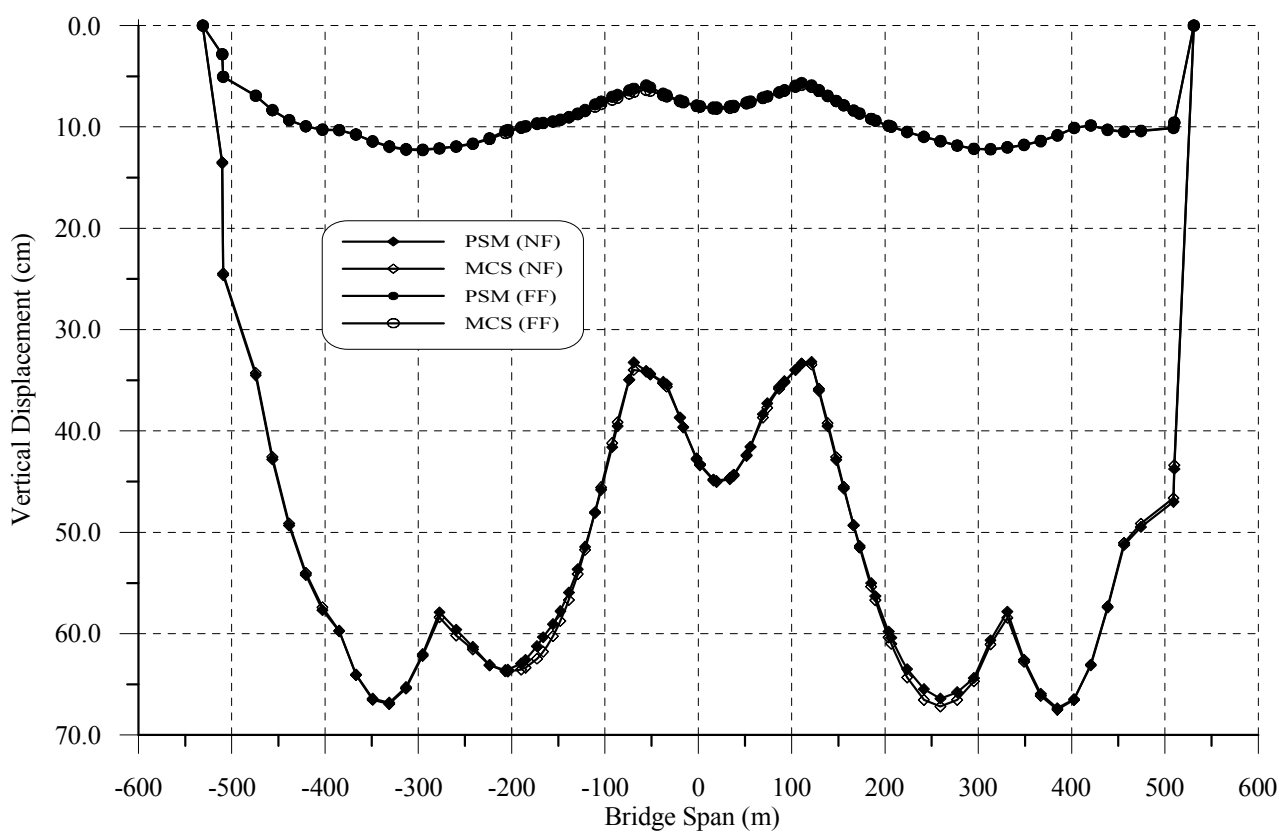

(a)

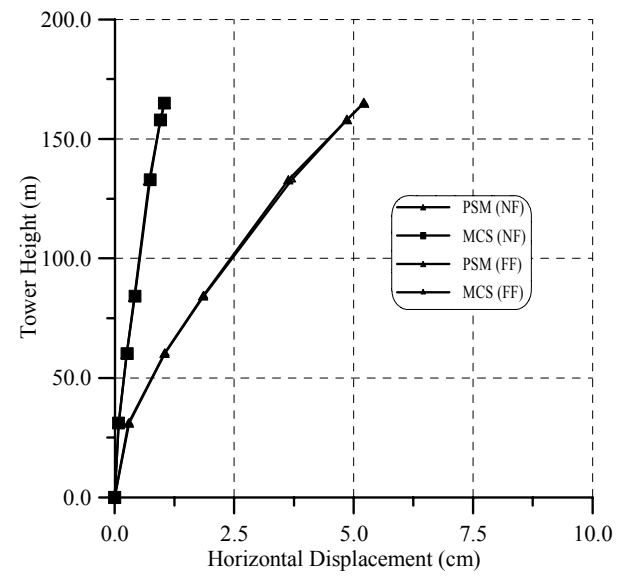

(b)

Fig. 8. Maximum sensitivity vertical displacements at the deck of Bosporus Bridge (a) and maximum horizontal displacements along Bosporus European tower (b) for random elastic modulus.

As the deck, towers, and cables of the selected bridge are modeled by beam elements; the hangers are modeled by truss elements. A finite element model of the bridge with 144 nodal points, 142 beam elements and 60 truss elements are used in the analyses (Fig. 11). This model has three degrees of freedom at each nodal point, namely, two translational degrees of freedom in vertical and longitudinal axes and one rotational degree of freedom in lateral axis. So, the finite element model of the bridge is decreased to 418 degrees of freedom and therefore a 2-D analysis is adopted in the vertical plane of the bridge.

YPT-UP and GBZ-UP component of the 17 August 1999, Kocaeli, Turkey earthquake (Figs. 2-3) are chosen as ground motion since it took place at the vicinity of the bridges. For earthquake response analysis of many types of structures, the vertical component of ground motion may not be important. For long-span bridges like suspension bridges, however, vertical ground motion is important. In this study, only the vertical component of the ground motion is applied to the bridge to determine the vulnerability of this bridge to earthquake ground motion.

Suspension bridges are not structurally homogeneous like buildings and dams. It was concluded from previous studies that the tower, deck and cables affect the structural response in a wide range of modes. The number of modes plays a very important role in obtaining the results with acceptable 


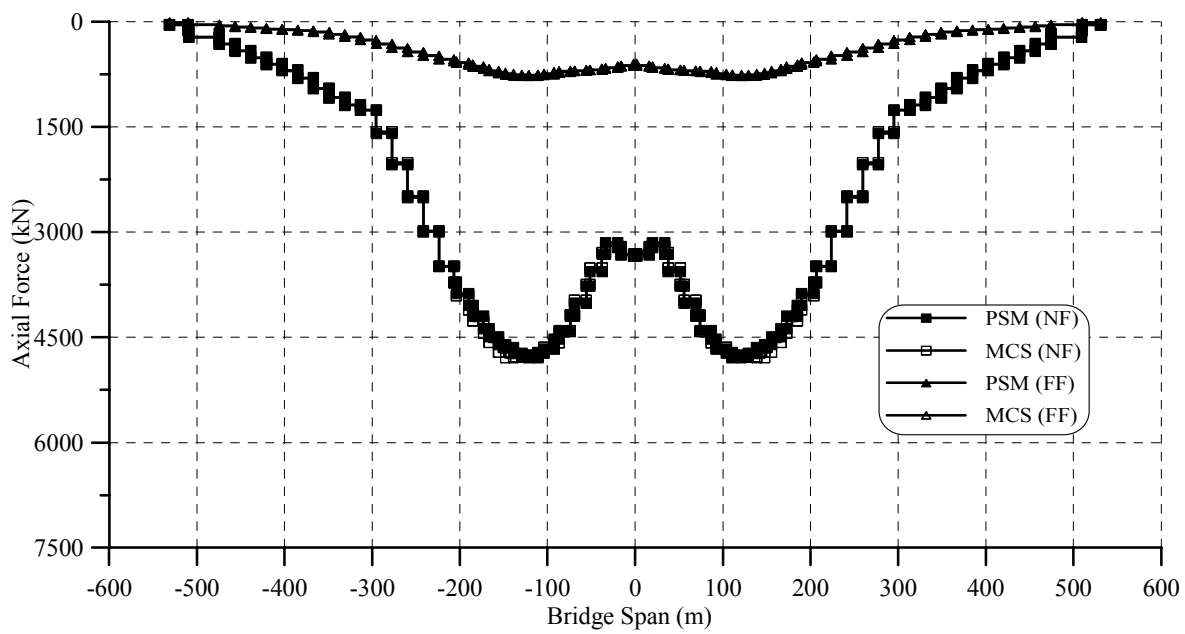

(a)

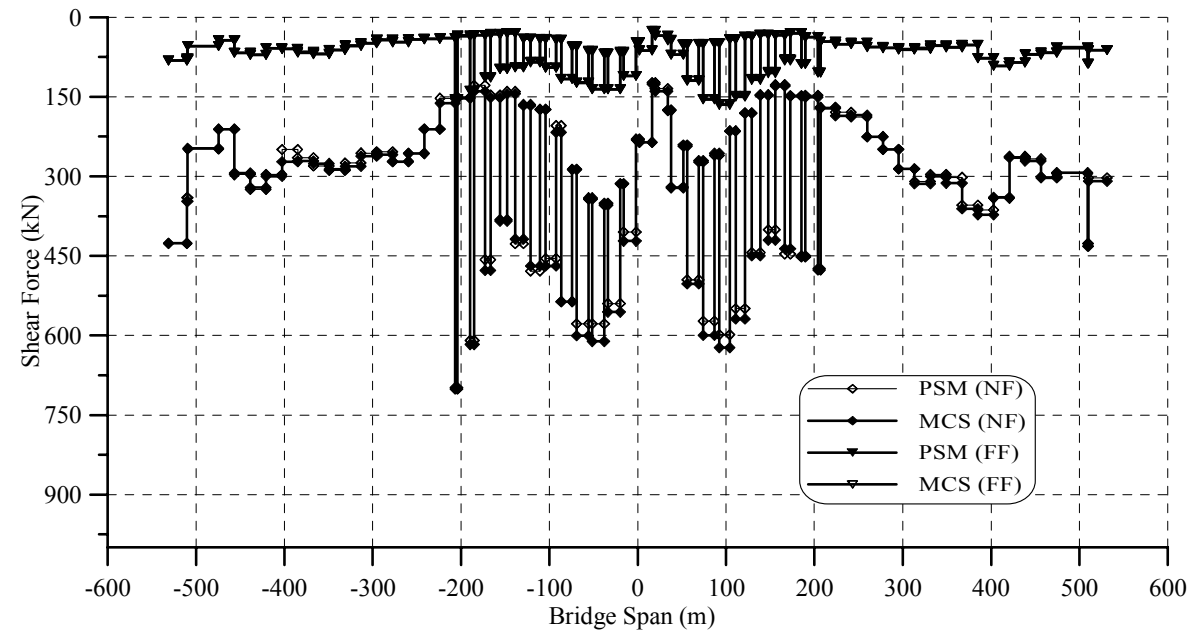

(b)

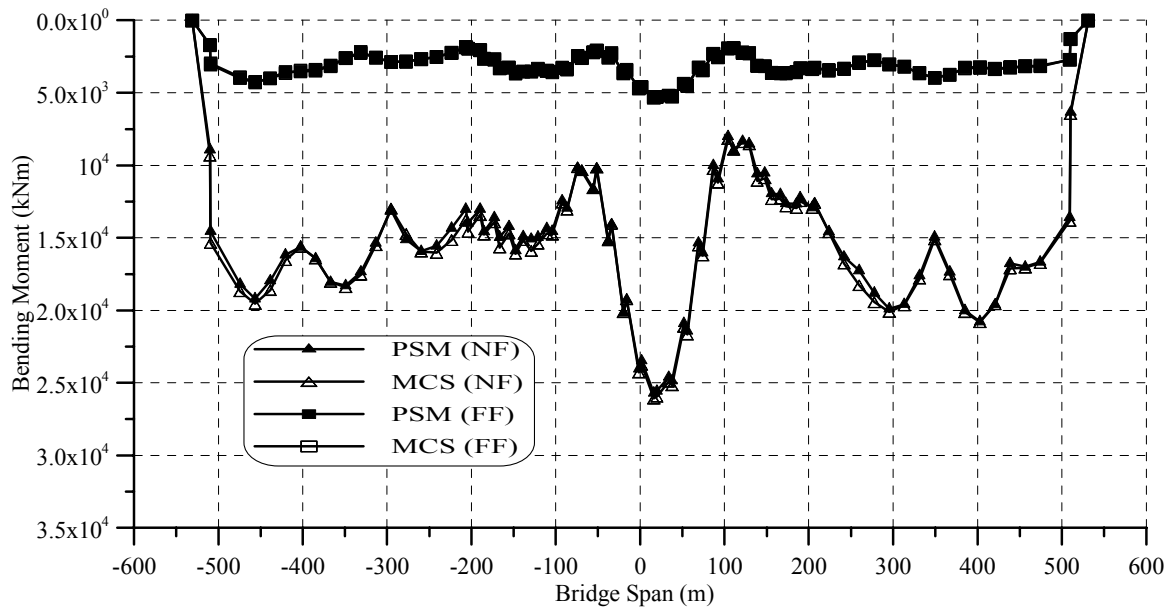

(c)

Fig. 9. Maximum sensitivity axial forces (a), shear forces (b) and bending moment (c) for deck of Bosporus Bridge for random elastic module (E). 

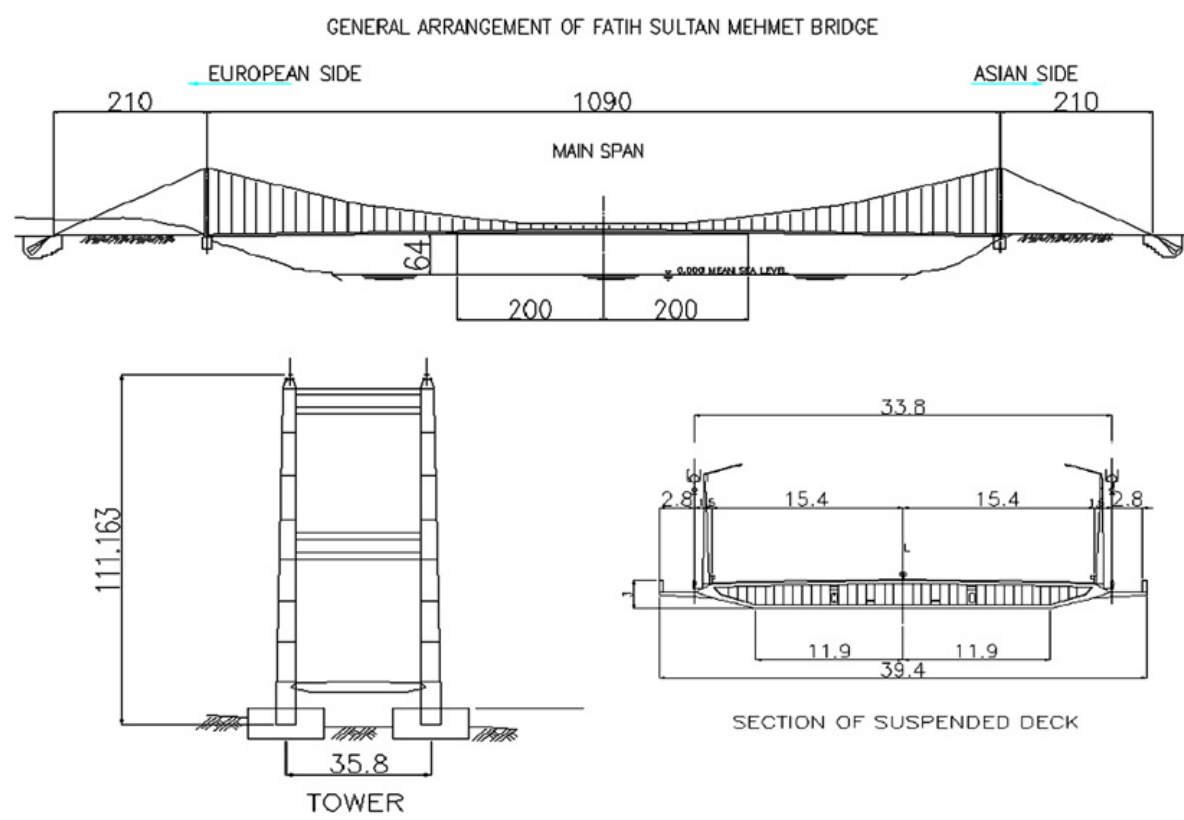

SECTION OF SUSPENDED DECK

Fig. 10. General arrangement of Fatih Sultan Mehmet Suspension Bridge.

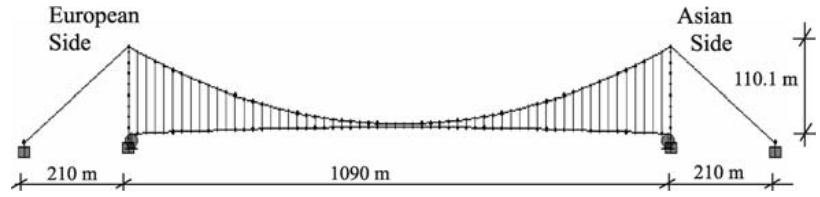

Fig. 11. 2-D finite element model of Fatih Sultan Mehmet suspension bridge.

accuracy (Brownjohn and Dumanoğlu, 1992). So, the first 20 modes of vibration are adopted for the response calculations.

The elastic module from material properties is chosen as the random variable for the Fatih Sultan Mehmet suspension bridge. The other variables are considered as deterministic. This random variable is assumed to follow a normal distribution with the coefficient of variation 0.10 . The respective expectation and correlation function and coefficient of variation (Çavdar et al., 2010) for the elastic modulus $E_{\rho}$ are assumed as follows:

$$
E\left[E_{\rho}\right]=2.1 \times 10^{8} \quad \lambda=10
$$

$\mu\left(E_{\rho}, E_{\sigma}\right)=\exp \left(-\frac{\left|x_{\rho}-x_{\sigma}\right|}{\lambda l}\right) \quad \rho, \sigma=1,2, \ldots, 186$

$\alpha=0.10$

where $x_{\rho}, l$ and $\lambda$ are ordinates of the element midpoints ( $\mathrm{n}$ random variable, $\rho, \sigma=1,2, \ldots, n)$, structural member length and decay factor, respectively. The Fatih Sultan Mehmet suspension bridge is modeled by 186 probabilistic finite elements with different lengths. Consistent with modeling parameters for the Bosporus Bridge, MCS method is simulated for 10000 simulations. With the 2-D time-instant sensitivity response of the structural system of Fig. 11, the structural response functional is defined as

$$
\varphi(\tau)=\frac{\left[q_{\beta}(\tau)\right]^{2}}{\left(q_{b} \text { eta }(A)\right)^{2}-1 \leq 0}
$$

where $q_{\beta}(\tau)$ is vertical displacement at the apex A and $q_{\beta}^{(A)}$ is an admissible displacement value.

The elastic module is assumed to be random design variables.

In the second part of this study, Fatih Sultan Mehmet Bridge's probabilistic sensitivity responses with respect to random elastic modulus according to PSM and MCS methods are determined and compared with each other. The maximum probabilistic sensitivity vertical displacement responses of the bridge deck and horizontal displacements along the Fatih Sultan Mehmet European tower obtained from PSM and MCS methods for NF and FF ground motions are presented in Fig. 12. It is shown from Fig. 12 that the probabilistic sensitivity displacement values for NF ground motion are greater than those for FF ground motion, although the peak ground acceleration of NF and FF records is the same. The maximum sensitivity horizontal displacements at the tower for NF and FF ground motions occur as $1.65 \mathrm{~cm}$ and $5.30 \mathrm{~cm}$, respectively. This situation is valid for both the PSM and MCS response. The maximum probabilistic sensitivity displacements for the records of YPT-UP and 


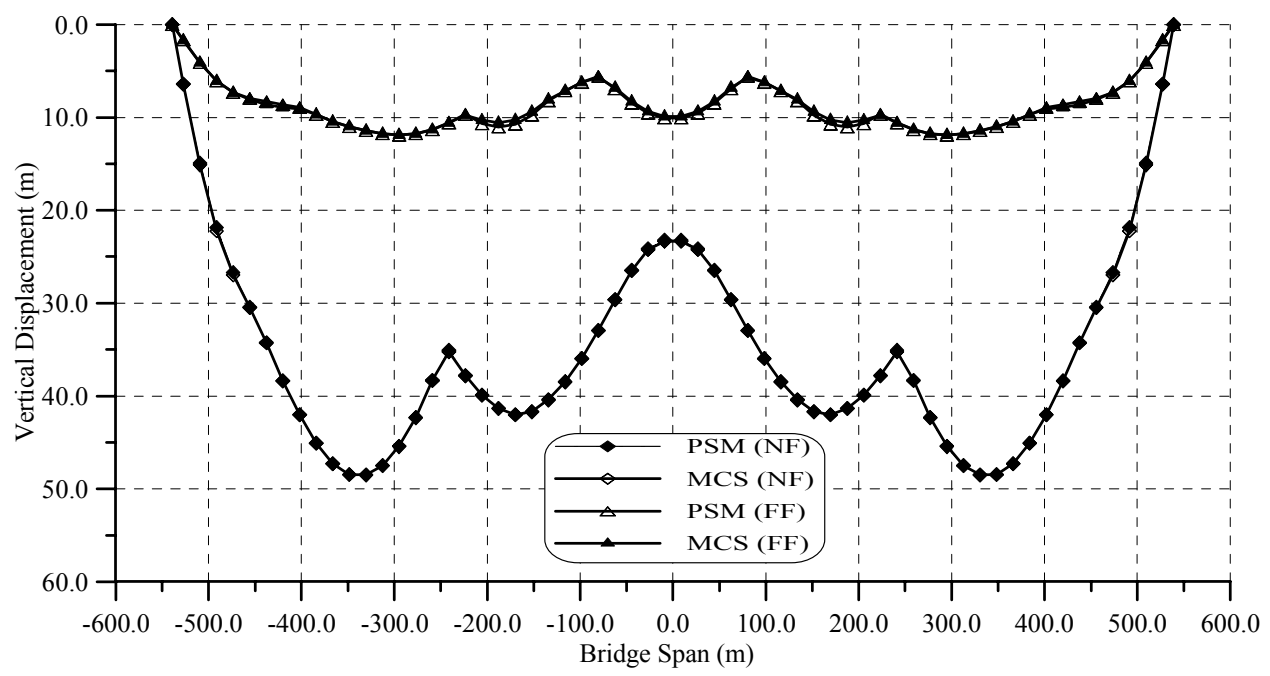

(a)

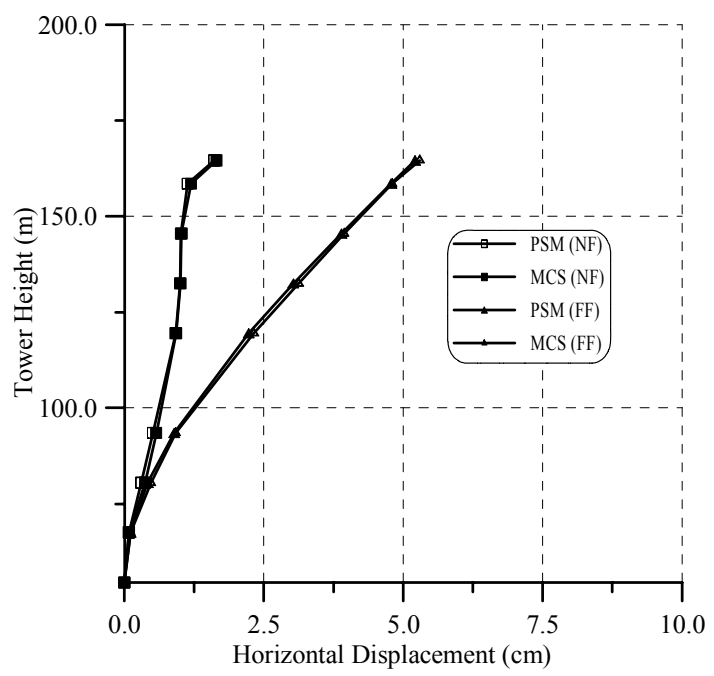

(b)

Fig. 12. Maximum sensitivity vertical displacements at the deck of Fatih Sultan Mehmet Bridge (a) and maximum horizontal displacements along Fatih Sultan Mehmet European tower (b) for random elastic modulus.

GBZ-UP of the Kocaeli earthquake occur as $48.50 \mathrm{~cm}$ and $11.89 \mathrm{~cm}$, respectively. The average absolute differences between NF and FF ground motions for vertical displacement values are about $74 \%$ for PSM.

It can be seen from Fig. 12 that the maximum values of probabilistic dynamic sensitivity responses for the random elastic module are very similar to the result from the MCS method. For accurate dynamic responses, it is necessary that the analysis technique incorporate the effect of structural parameter randomness. This has special importance for accurate probabilistic dynamics sensitivity of complex systems, which exhibit wide dispersion in structural parameters.

The maximum probabilistic sensitivity axial forces, shear forces and bending moments at the deck of the Fatih Sultan
Mehmet Bridge obtained from probabilistic dynamics sensitivity analysis subjected to each ground motion are presented Fig. 13. The probabilistic sensitivity variations of the internal forces with deck distance are plotted separately for both near-fault and far-fault ground motions, as shown in Fig. 13. In this figure, PSM and MCS responses are compared to each other. As seen from the figure, the maximum probabilistic axial forces, shear forces and bending moment calculated for the YPT-UP component of NF ground motion are greater than those for FF ground motion at the deck of the Fatih Sultan Mehmet Bridge.

The results obtained from the probabilistic dynamics sensitivity analysis of the suspension bridges show that the probabilistic sensitivity displacement values for near-fault ground 


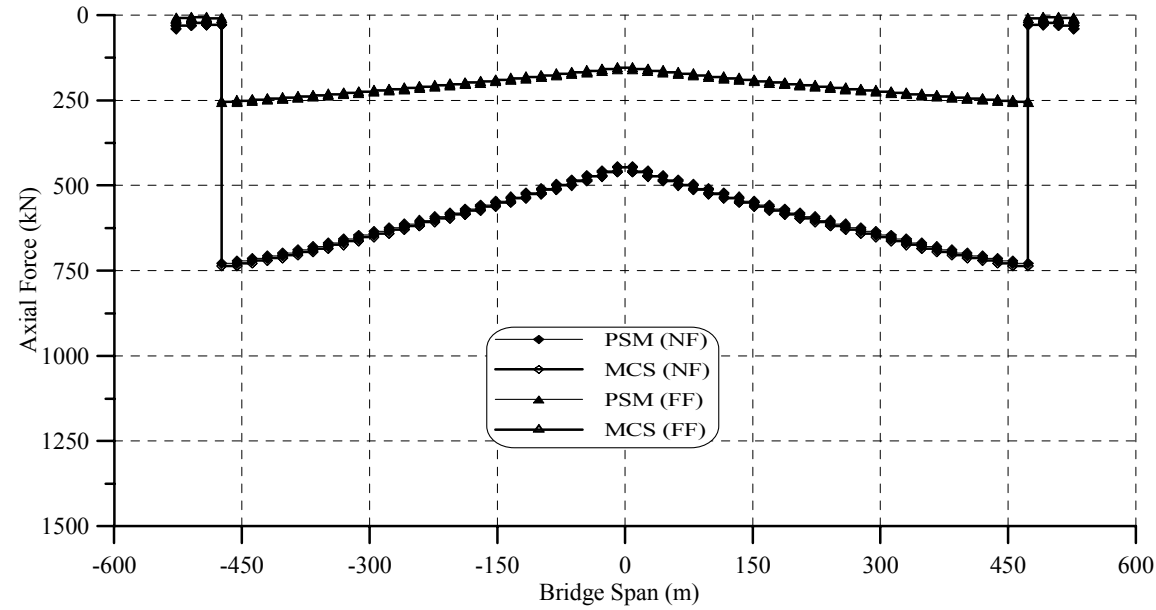

(a)

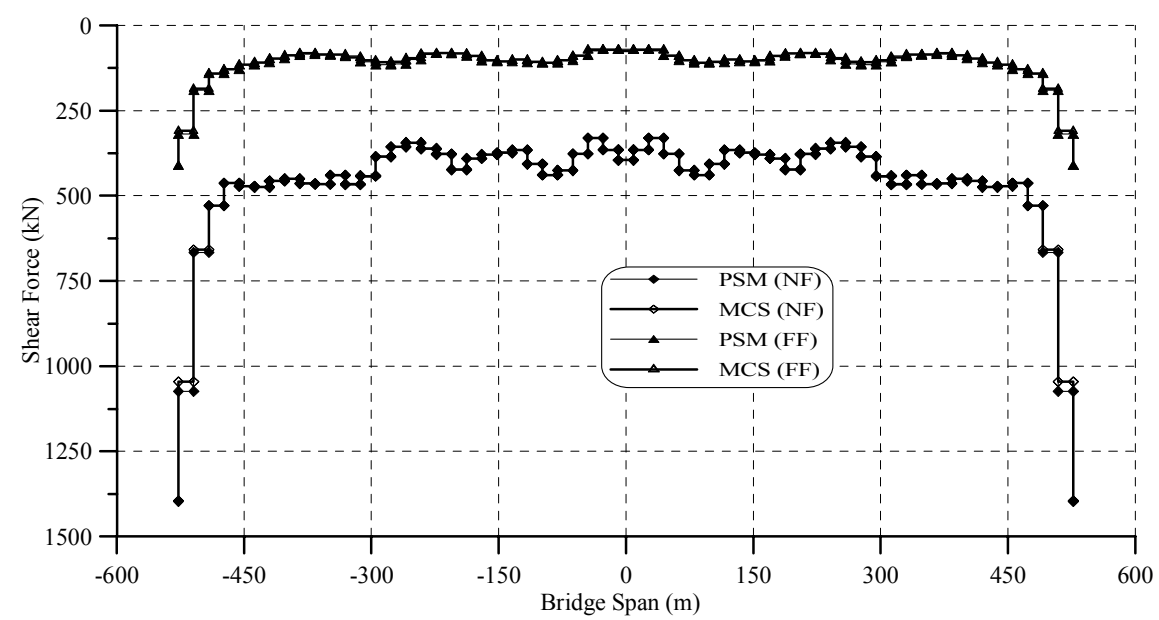

(b)

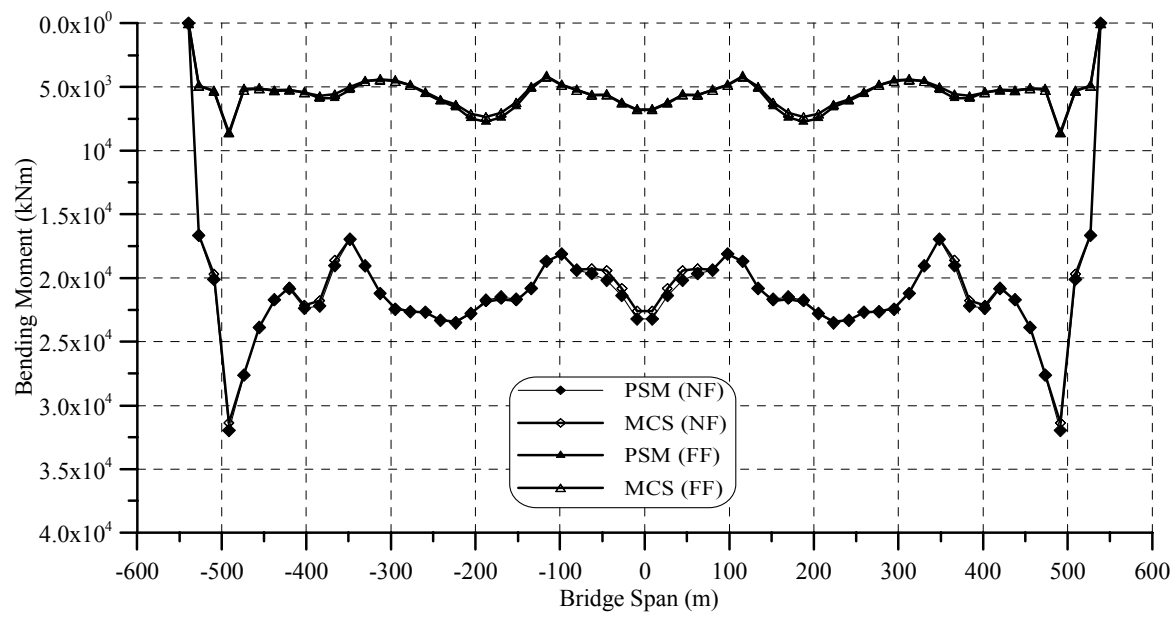

(c)

Fig. 13. Maximum sensitivity axial forces (a), shear forces (b) and bending moment (c) for deck of Fatih Sultan Mehmet Bridge for random elastic module (E). 
motion are greater than those for far-fault ground motion, although the peak ground acceleration of near-fault and farfault records are the same.

It should be mentioned that for the other results obtained for these examples, for the Bosporus Suspension Bridge system whose numerical properties are presented (Fig. 7), about $8 \mathrm{~s}$ are needed for probability dynamic sensitivity analysis subjected to NF and FF ground motion. However, about $11 \mathrm{~h}$ are needed for MCS analysis with a PC that has Intel Core 2 Duo CPU P8600 2.40 GHz and 2.00 GB RAM. For the probabilistic sensitivity analysis of the Fatih Sultan Mehmet Suspension Bridge system whose numerical properties are given (Fig. 10), about $5 \mathrm{~s}$ are needed for the PSM; however, about $9 \mathrm{~h}$ are needed for the MCS analysis of 10000 simulations.

The probabilistic sensitivity responses obtained show that selected correlation function suitable for this example for chosen coefficient of variation (COV) value $(\alpha=0.10)$.

The examples clearly demonstrate the efficiency, robustness and desirability application potential of the proposed PSM-based algorithm. The algorithm can be used routinely for the probabilistic forced vibration analysis and design of the complex suspension bridges as an alternative to the currently available methods.

\section{Conclusions}

In this study, probabilistic sensitivity responses of two suspension bridges subjected to both near-fault and far-fault ground motions are investigated. The Bosporus and Fatih Sultan Mehmet suspension bridges in Turkey are chosen for analyses. These two suspension bridges are modeled by the probabilistic finite element method. Stochastic dynamics sensitivity analyses of suspension bridges are realized by using PSM and MCS methods. For this purpose, two-dimensional probabilistic finite element models of both bridges are prepared in the same study and the results of the probabilistic dynamics sensitivity analysis are presented. In addition to this, accuracy of it has been checked by comparing to other analytical method (MCS).

This study confirms the importance of the ground motion selection for the accurate evaluation of the probabilistic dynamics sensitivity performance of suspension bridges. It should be clarified that the NF and FF ground motion effects appear for the duration of the earthquake. The results obtained from the probabilistic dynamics sensitivity analysis of the suspension bridges show that the displacement values and internal forces for NF ground motion are greater than those for FF ground motion, although the peak ground acceleration of NF and FF records are the same. In light of the presented results, it is apparent that the probabilistic sensitivity response of the selected suspension bridges subjected to NF ground motion is greater affected than those subjected to FF ground motion.
According to this study, the earthquake record of the NF and FF ground motion, forming of the combination of numerous waves, has a remarkable effect on the probabilistic sensitivity earthquake response of the suspension bridges. It is seen from the conclusions of this study that different NF and FF strong ground motion records should be considered in the probabilistic dynamic sensitivity analysis of complex suspension bridges.

The presented numerical technique is well suited for computer-aided analysis for structural systems. The Probabilistic Sensitivity Method (PSM) is very effective, as it provides sufficient accuracy for a small range of chosen coefficient of variation (COV). For the suspension bridges modeled in this study, the PSM gives close results to the MCS method for probabilistic sensitivity displacements and internal forces. With the numerical applications in this study, it is shown that the PSM is able to provide, at an attractive computational cost, a good estimation of the sensitivity response variability.

Finally, the probabilistic dynamics sensitivity analysis can identify the degree of robustness of the final design with respect to randomness of selected system parameters. This information can be used to determine whether system parameters uncertainty should be considered explicitly in the structural design process. The probabilistic sensitivity information provides a deeper insight into the structural design and it can be used as a basis for decision-making.

Edited by: M. E. Contadakis

Reviewed by: two anonymous referees

\section{References}

Adanur, S.: Geometrically nonlinear deterministic and stochastic analyses of suspension bridges to multiple support seismic excitations, PhD. Thesis, Karadeniz Technical University, 2003.

Agrawal, A. K. and He, W. L.: A closed-form approximation of near-fault ground motion pulses for flexible structures, 15th ASCE Engineering Mechanics Conference, New York, 2002.

Apayd $\iota n$, N.: Seismic Analysis of Fatih Sultan Mehmet Suspension Bridge, Ph.D. Thesis, Department of Civil Engineering, Boğaziçi University Istanbul, Turkey, 2002.

Bayraktar, A., Altun $\iota$ k, A. C., Sevim, B., Kartal, M. E., and Turker, T.: Near-fault ground motion effects on the nonlinear response of dam-reservoir-foundation systems, Struct. Eng. Mech., 28, 4, 411-442, 2008.

Bertero, V. V., Mahin, S. A., and Herrera, R. A.: A seismic design implications of near-fault San Fernando earthquake records, Earthq. Eng. Struct. Dyn., 6, 31-42, 1978.

Brownjohn, J. M. W., Dumanoğlu, A. A., and Severn, R. T.: Ambient vibration survey of the Fatih Sultan Mehmet (SecondBosporus) suspension bridge, Earthquake Eng. Struct. Dynam., 21, 10, 907-924, 1992.

Çavdar, Ö., Bayraktar, A., and Adanur, S.: Stochastic finite element analysis of a cable-stayed bridge system with varying material properties, Probabilist. Eng. Mech., 25, 279-289, 2010. 
Cheng, J. and Xiao, R. C.: Probabilistic free vibration and flutter analyses of suspension bridges, Eng. Struct., 27, 1509-1518, 2005.

Chopra, A. K. and Chintanapakdee, C.: Comparing response of SDF systems to near-fault and far-fault earthquake motions in the context of spectral regions, Earthquake Eng. Struct. Dynam., 30, doi:10.1002/eqe.92, 2001.

Corigliano, M., Lai, C. G., and Barla, G.: Seismic response of rock tunnels in near-fault conditions, in: First European Conference on Earthquake Engineering and Seismology, Geneva, Switzerland, 3-8 September, 2006.

Dicleli, M. and Buddaram, S.: Equivalent linear analysis of seismicisolated bridges subjected to near-fault ground motions with forward rupture directivity effect, Eng. Struct., 29, 21-32 2007.

Dumanoglu, A. A. and Severn, R. T.: Stochastic response of suspension bridges to earthquake forces, Earthquake Eng. Struct. Dynam., 19, 133-152, 1990.

Hall, J. F., Heaton, T. H., Halling, M. W., and Wald, D. J.: Nearsource ground motion and its effects on flexible buildings, Earthq. Spectra, 11, doi:10.1193/1.1585828, 1995.

Hien, T. D. and Kleiber, M.: Stochastic design sensitivity in structural dynamics”, Int. J. Numer. Methods Eng., 32, 1247-1265, 1991.

Juhn, G. and Manolis, G. D.: Stochastic sensitivity and uncertainty of secondary systems in base-isolated structures, J. Sound. Vibration, 159, 207-222, 1992.

Kleiber, M. and Hien, T.: The stochastic finite element method, John Wiley and Sons, New York, USA, 1992.

Liao, W. I., Loh, C.-H., and Wan, S.: Earthquake responses of moment frames subjected to near-fault ground motions, Struct. Des. Tall Build., 10, 219-229, 2001.
Liao, W. I., Loh, C. H., and Lee, B. H.: Comparison of dynamic response of isolated and non-isolated continuous girder bridges subjected to near-fault ground motions, Eng. Struct., 26, doi:10.1016/j.engstruct.2004.07.016, 2004.

Liu, C. H., Wang, T. L., and Qin, Q.: Study on sensitivity of modal parameters for suspension bridges, Struct. Eng. Mech., 8, 453464, 1999.

Malhotra, P. K.: Response of buildings to near-field pulselike ground motions, Earthquake Eng. Struct. Dynam., 28, doi:10.1002/(SICI)1096-9845(199911)28:11<1309::AIDEQE868>3.3.CO;2-L, 1999.

Megawati, K., Higashihara, H., and Koketsu, K.: Derivation of near-source ground motions of the 1995 Kobe (Hyogo-ken Nanbu) earthquake from vibration records of the Akashi Kaikyo Bridge, and its implications, Eng. Struct., 23, 1256-1268, 2001.

Melchers, R. E. and Ahammed, M.: A fast approximate method for parameter sensitivity estimation in Monte Carlo structural reliability, Comput. Struct, 82, 55-61, 2004.

Özturk, B.: A simple procedure for the assessment of seismic drift response of building structures located in seismically active and near-fault regions, in: First European Conference on Earthquake Engineering and Seismology, Geneva, Switzerland, 3-8 September, 2006.

PEER (Pacific Earthquake Engineering Research Centre), http:// peer.berkeley.edu/smcat/data, 2011.

Shinozuka, M.: Monte Carlo Simulation of structural dynamics, Comput. Struct., 865-874, 1972.

Somerville, P. G.: Magnitude scaling of the near-fault rupture directivity pulse, Phys. Earth Planet. Inter. 137, 201-212, 2003.

Wang, G.-Q., Zhou, X.-Y., Zhang, P.-Z., Igel, H.: Characteristics of amplitude and duration for near-fault strong ground motion from the 1999 Chi-Chi, Taiwan earthquake, Soil Dyn. Earthq. Eng., 22, 73-96, 2002. 